\title{
ESPIRITUALIDADE E RESILIÊNCIA EM PACIENTES ONCOLÓGICOS
}

\author{
Maria Tereza Soratto \\ Dipaula Minotto da Silva \\ Paula Ioppi Zugno \\ Raquel Daniel
}

Universidade do Extremo Sul de Santa Catarina (UNESC) - Criciúma (SC), Brasil.

E-mail: guiga@unesc.net
RESUMO: Resiliência significa a capacidade de recuperar-se de adversidades, força, resistência, superação diante do processo de adoecimento. Este estudo configura-se em pesquisa com objetivo de identificar a importância da espiritualidade na resiliência em pacientes oncológicos internados em uma unidade oncológica hospitalar. Trata-se de pesquisa de campo com abordagem qualitativa descritiva. O estudo foi desenvolvido com dez (10) pacientes em tratamento em uma clínica de internação oncológica de um hospital de grande porte e alta complexidade da Região Sul de Santa Catarina. A análise dos dados foi realizada a partir da Técnica de Análise de Conteúdo. Os pacientes destacaram as dificuldades enfrentadas com o processo de adoecimento, relatando as transformações que surgiram na rotina familiar, nas atividades de vida diária e na própria fé em Deus. Os pacientes oncológicos consideram que existe influência da espiritualidade na resiliência para enfrentar o processo de adoecimento e tratamento. Cabe à enfermagem compreender e valorizar a relação entre espiritualidade e o enfrentamento do câncer. O cuidado espiritual em enfermagem pode ser considerado base da humanização da assistência, princípio norteador da ética do cuidar.

PALAVRAS-CHAVE: Câncer; Enfermagem; Espiritualidade; Resiliência.

\section{SPIRITUALITY AND RESILIENCE IN PATIENTS SUFFERING FROM CANCER}

ABSTRACT: Resilience is the ability to vanquish adversities, strength, resistance, overcoming in the wake of disease. Current research, featuring a descriptive and quality approach, identifies the importance of spirituality in resilience in patients with cancer and hospitalized in hospital cancer unit. Current analysis was developed with ten patients treated in a cancer clinic of a big, high complexity hospital in the southern region of the state of Santa Catarina, Brazil. Data analysis was undertaken with the Content Analysis Technique. Patients underscored the difficulties they had to cope with due to sickness and reported the transformations in family routine, daily life and their belief in God. People with cancer think that there is a spiritual influence on resilience to face the process of sickness and treatment. The nursing team should understand and valorize the relationship between spirituality and coping with cancer. Spiritual care in nursing must be considered the basis of humanization, the guiding principle in care ethics.

KEY WORDS: Cancer; Nursing; Spirituality; Resilience. 


\section{INTRODUÇão}

O Instituto Nacional do Câncer (INCA) estima que o câncer ganha uma grande relevância para o Brasil, cerca de aproximadamente 576 mil novos casos para o ano de 2015 (SILVA, 2014, p. 25).

$\mathrm{O}$ diagnóstico do câncer provoca vários sentimentos contraditórios no paciente, apesar do avanço da tecnologia, pois ainda é uma doença atrelada à terminalidade. O diagnóstico de câncer envolve várias fases enfrentadas pelo paciente: conflito; alterações relacionadas à vida diária; e a adaptação a todo o processo vivenciado. As transformações advindas com o câncer podem dar um novo significado à vida, com a valorização de aspectos antes não observados (SALCI; MARCON, 2011).

Nesta perspectiva, a espiritualidade e resiliência podem ser uma forma de estratégia de enfrentamento de cada paciente perante seu diagnóstico, onde o próprio paciente poderá atribuir significado ao seu processo de cura-doença, em busca da qualidade e sobrevivência se apegando à fé, para aliviar o sofrimento e, assim, obter maior esperança/expectativa de cura durante o tratamento, enfrentamentos estes adquiridos na vida social (GERRERO et al., 2011).

Os pacientes oncológicos passam por muitos períodos de descoberta até o tratamento da doença; após a confirmação do diagnóstico o paciente vê sua vida tomar um rumo diferente. Primeiramente passam por estado de choque, depois percebem que é real, muitas das vezes relutam contra a ideia, mas depois acabam aceitando e planejando um futuro com esperança (GERRERO et al., 2011).

Atualmente o câncer é considerado como um possível precipitante de sintomas da perturbação de estresse pós-traumático sendo este no doente como nos familiares em primeiro grau (TEIXEIRA; PEREIRA, 2011).

A resiliência e a fé são formas que o paciente encontra como uma fonte de apoio para o enfrentamento do câncer, bem como para conseguir suportar os desafios provocados pelos tratamentos, ou até mesmo confortarem-se diante da possibilidade de morte. Assim, a fé e a resiliência passam a ser um instrumento extremamente importante para o paciente e sua família no enfrentamento perante o diagnóstico, pela sua capacidade de propor- cionar conforto e esperança na superação dos obstáculos impostos pela doença (SALCI; MARCON, 2011).

A atuação em oncologia requer da equipe de enfermagem mais que conhecimentos teóricos e práticos; exige o desenvolvimento de habilidades que possam nortear a sua atuação profissional, considerando as dimensões físicas, emocionais, sociais e espirituais dos pacientes sob sua responsabilidade, com uma doença crônica, com demandas contínuas e imprevisíveis (SILVA; CRUZ, 2011).

A partir de experiência em estágio curricular no setor de oncologia, percebeu-se o grande impacto do câncer na vida do paciente e a importância da espiritualidade na resiliência dos pacientes. A espiritualidade serve como força de luta para enfrentar todo o processo de adoecimento e tratamento do câncer. Quando o paciente já não tem forças para enfrentar a doença, a fé é primordial para a continuidade do tratamento. O processo de adoecimento traz muito sofrimento e transformações na vida do paciente e familiar, transformações estas em nível de valores espirituais em que o amor e o vínculo se constroem em alicerce para vencer o sofrimento e a dor, tanto do paciente quanto de seus familiares. Nessa concepção considera-se essencial que a enfermagem possa ser apoio e conforto a este paciente e familiares em sofrimento. O apoio e conforto devem ser pautados também na espiritualidade.

A relevância da crença, da fé e da religião e a resiliência podem ser utilizadas pelo profissional da enfermagem como estratégia para alavancar as carências de cada paciente e, com isso, possa planejar, orientar e fornecer uma assistência mais apropriada a cada paciente de acordo com sua necessidade (GERRERO et al., 2011).

A resiliência vem abrangendo várias áreas de interesse, representando um novo espaço de investigação. Essa visão valoriza as intervenções mais tardias, como ferramentas para ampliar a capacidade dos indivíduos de enfrentar as adversidades e conflitos inerentes à sua existência (SORIA et al., 2009).

Neste contexto, o presente estudo objetivou identificar a importância da espiritualidade na resiliência em pacientes oncológicos internados em uma unidade oncológica hospitalar. 


\section{MATERIAL E MÉTODOS}

Trata-se de pesquisa de abordagem qualitativa, descritiva e de campo. O estudo foi desenvolvido com dez (10) pacientes com câncer internados em uma clínica de internação oncológica de um hospital de grande porte e de alta complexidade da Região Sul de Santa Catarina. Foram utilizados como critérios de inclusão: paciente em tratamento na clínica oncológica do hospital, paciente lúcido e orientado em condições de responder à entrevista e que aceitaram participar da pesquisa e assinaram o Termo de Consentimento Livre Esclarecido (TCLE).

A análise e interpretação dos dados foi realizada tendo em vista elementos oferecidos pela análise de conteúdo a partir da categorização dos dados (MINAYO, 2009).

Para preservar o sigilo decorrente das entrevistas realizadas, de acordo com as diretrizes e normas regulamentadoras da Resolução $n^{\circ}$ 466/12, que envolvem pesquisa com Seres Humanos e Grupos Vulneráveis, utilizou-se a letra "P" para os pacientes, seguido do respectivo número - P1 a P10.

A pesquisa foi aprovada pelo Comitê de Ética em Pesquisa da UNESC pelo Projeto $n^{0} 887.990 / 2014$.

\section{RESULTADOS E DISCUSSÃO}

\subsection{PERFIL DOS PACIENTES ENTREVISTADOS}

Em relação ao perfil dos pacientes entrevistados, quatro são do sexo feminino e seis são do sexo masculino, a idade variou de 35 a 77 anos, oito são casados, uma é viúva e uma é solteira, conforme destacado no quadro 1.

Quadro 1. Caracterização do perfil dos pacientes oncológicos

\begin{tabular}{|c|c|c|c|c|c|c|}
\hline Paciente & Sexo & Idade & Estado Civil & Escolaridade & Religião & Tipo de Câncer \\
\hline P1 & F & 48 & Casada & $2^{\text {o }}$ grau & Católica & Câncer de mama \\
\hline P2 & M & 51 & Casado & $1^{\text {o }}$ grau & Evangélico & Câncer de fígado \\
\hline P3 & F & 58 & Viúva & $8^{\text {a } \text { série }}$ & Católica & Câncer de garganta \\
\hline P4 & M & 57 & Casado & $2^{\text {o }}$ grau & Católico & Câncer de fígado e pâncreas \\
\hline P5 & M & 56 & Casado & $5^{\text {a } \text { série }}$ & Católico & Câncer no rosto \\
\hline P6 & M & 53 & Casado & $4^{\text {a } \text { série }}$ & Evangélico & Câncer de intestino \\
\hline P7 & M & 77 & Casado & $3^{\text {a } \text { série }}$ & Católico & Câncer na bexiga \\
\hline P8 & M & 53 & Casado & $4^{\mathrm{a}}$ série & Católico & Câncer de faringe \\
\hline P9 & F & 35 & Solteira & $1^{\text {o } \text { grau }}$ & Católica & Câncer tumor lombar \\
\hline P10 & F & 45 & Casada & $3^{\text {a } \text { série }}$ & Evangélica & Câncer na bexiga \\
\hline
\end{tabular}

Fonte: Dados da pesquisa, 2015.

Quanto à escolaridade dois pacientes possuem o $2^{\circ}$ grau (P1 e P4) e dois o $1^{\circ}$ grau (P2 e P9); os restantes possuem $1^{\circ}$ grau incompleto.

Em relação ao tipo de câncer, dois pacientes possuem câncer de bexiga (P7 e P10); outros dois possuem câncer de fígado (P2 e P4), sendo que o paciente P4 também possui câncer de pâncreas. Os demais pacientes apresentam tipos de câncer variados: mama (P1); garganta (P3); rosto (P5); intestino (P6); faringe (P8); tumor lombar (P9).

\subsection{O IMPACTO DO DIAGNÓSTICO DA DOENÇA NA VIDA DO PACIENTE}

Todos os pacientes relataram a grande mudança ocorrida com o diagnóstico de câncer, o desespero da família (P3; P8) e as mudanças ocorridas na estrutura familiar (P1; P2; P3).

P1: "Foi muito grande, as rotinas mudaram completamente minha e de toda família". 
P2: "Mudou toda estrutura familiar e eu inclusive, meu organismo".

P3: "Mudou todo contexto familiar, minhas filhas se desesperaram".

P4: "Tudo mudou toda rotina, procuro fazer o que posso, mas é difícil".

P6: "Mudou toda minha rotina, fazia de tudo e agora tive que parar".

P7: "Mudou toda minha vida, as coisas que fazia antes boje não faço mais".

P8: "Mudou toda rotina, minha família ficou desesperada ninguém consegue aceitar eu tento me conformar".

P9: "Total, boje não faço mais nada sozinha que fazia antes só com ajuda, até xixi tem que ser por sonda".

P10: "Parou com minha vida, não tem roupas que sirvam, minba barriga incha fico enorme e não tem o que fazer".

Não é somente o indivíduo que sofre, mas sim toda a sua família compartilha desse impacto emocional juntamente com seu ente querido. Destaca-se que a descoberta do câncer não acontece sem a partilha principalmente da família e da rede de suporte social mais próxima, pois o mesmo desencadeia mudanças em todo o contexto familiar, de forma que todos os integrantes, em maior ou menor grau, são afetados pela nova situação (SALCI; MARCON, 2011).

Destaca-se na fala do paciente P5 a interferência da dor em virtude do câncer nas atividades de vida diária, além do medo do sofrimento diante do processo de adoecimento:

P5: "Ficou difícil, pois gostava de trabalhar, pescar e agora dói muito quando vou tentar fazer alguma coisa. Perdi muito peso e fiz vários enxertos, mesmo assim não tenho medo de morrer e sim medo de sofrer ainda mais do que estou, todo mundo quer viver mais com saúde".

Muitas vezes, o paciente projeta os pensamentos além do momento presente e visualiza que as possibi- lidades que o futuro lhe reserva podem ser ainda mais sofridas, pois os planos para o futuro ficam ameaçados de não acontecer. Isso porque o câncer é uma doença percebida no senso comum como incurável, perigosa e horrivel, além de provocar a morte após longo sofrimento e, com isso, transtornos em todo o contexto familiar (SALCI; MARCON, 2011).

"O alívio da dor é atualmente visto como um direito humano básico e, portanto, trata-se não apenas de uma questão clínica, mas também de uma questão ética e moral que envolve todos os profissionais de saúde" (SILVA et al., 2014, p. 130).

\subsection{A ADAPTAÇÃO DO PACIENTE NO DECORRER DO PROCESSO DE ADOECIMENTO E TRATAMENTO}

Todos os pacientes destacaram as dificuldades enfrentadas com o processo de adoecimento.

P3: "Muito ruim cada dia mais difícil".

P4: "Não tive outro jeito, tive que me adaptar à nova realidade, cada dia mais fica difícil, aos poucos vai deixando de fazer muitas coisas, tento me conformar".

P9: "Difícil, não consigo me adaptar".

P10: "Difícil".

O câncer é uma neoplasia maligna, ainda de difícil aceitação por todos, com isso traz vários significados, sempre negativos na maioria das vezes (GERRERO et al., 2011).

Destaca-se no relato dos pacientes $\mathrm{P} 2, \mathrm{P} 6, \mathrm{P} 7$ e P8 a interferência da nutrição relacionada ao processo de adoecimento.

P2: "Está sendo cada dia mais ruim, perda de peso de apetite e vômitos".

P6: "É muito ruim, perdi muito peso, fico vários dias sem comer, minha boca enche de feridas".

P7: "Foi uma luta, perda de cabelo, emagrecer e ânsias de vômitos".

P8: "Difícil, sinto ânsias de vômitos, às vezes não me alimento porque sei que daqui a pouco vou vomitar tudo para fora, não tenbo apetite". 
São múltiplas as causas que interferem no apetite das pessoas com câncer, levando à perda de apetite, a chamada anorexia: alterações do metabolismo, náuseas, vômitos, boca seca, dificuldade para engolir, efeitos colaterais da quimioterapia e da radioterapia, dor, fadiga e uso de sedativos (MALUF; BUZAID; VARELLA, 2015).

Ressalta-se que os pacientes $\mathrm{P} 6$, com câncer de intestino, e P8, com câncer na faringe, estavam realizando quimioterapia durante a pesquisa; o paciente $\mathrm{P} 7$, com câncer de bexiga, quimioterapia e radioterapia; o paciente P2, com câncer de fígado, estava utilizando medicamentos para dor.

Nas doses habituais, a maioria dos quimioterápicos pode causar náuseas e vômitos nos dias que se seguem à administração de cada ciclo, assim como a radioterapia aplicada em órgãos do abdômen e da pelve (INCA, 2014; MALUF; BUZAID; VARELLA, 2015). Além destes efeitos a quimioterapia ainda pode causar aumento de peso ou diminuição, fraqueza, queda de cabelos, feridas na boca, diarreia, enjoo e tonturas (INCA, 2014).

Mucosites são inflamações da mucosa oral que podem provocar ulcerações, desconforto e dor forte. Alguns tipos de agentes quimioterápicos, depressão imunológica e radioterapia aplicada em tumores de cabeça e pescoço são suas principais causas (MALUF; BUZAID; VARELLA, 2015).

Radioterapia e quimioterapia causam queda de cabelo e dos pelos porque lesam as células dos folículos responsáveis pelo seu crescimento (MALUF; BUZAID; VARELLA, 2015).

A radioterapia pode provocar dores de cabeça, náuseas, tonturas, dor ao se alimentar, dificuldades de engolir, boca seca e até mesmo rouquidão, tosse seca, fraqueza, diarreias, cólicas e ardor ao urinar (PAULA JÚNIOR; ZANINI; 2012).

A paciente P1, 48 anos, em tratamento de câncer de mama, ressaltou a interferência da dor para a adaptação ao processo de adoecimento:

\section{P1: "Difícil, piorou ainda há dois anos as do- res aumentam".}

O câncer em estado avançado geralmente causa muita dor, podendo ser aguda ou crônica. Várias carac- terísticas do câncer podem afetar o equilíbrio mental e físico, como limitações na vida diária, efeitos colaterais dos quimioterápicos e perda de autoestima. O diagnóstico do câncer representa um evento catastrófico na vida das pessoas do qual terão que aprender a lidar com a ansiedade de uma doença que pode ser fatal aos efeitos colaterais aversivos do seu tratamento. A dor está presente na maioria dos pacientes oncológicos levando-os à perda de energia para executar atividades diárias (COSTA; CHAVES, 2012).

O questionamento sobre o porquê do sofrimento, o desespero frente à doença e a vontade inerente de morrer, destacou-se no relato impactante do paciente P5, 56 anos, com câncer no rosto:

P5: "Quando comecei meu tratamento me veio um grande desespero e fico me perguntando por que me veio isso, sou uma boa pessoa, nunca falei mal de ninguém, sempre trabalbei e nunca vou aceitar isso, só quero morrer".

Para esses pacientes, a condição do diagnóstico e sua associação com a morte e os efeitos adversos dos tratamentos podem desencadear quadros de ansiedade e depressão (SANTICHI et al., 2012).

Elizabeth Kübler-Ross, em sua experiência com pacientes terminais, descreveu as 5 fases que o paciente vivencia no processo de morte e morrer: negação, raiva, barganha, depressão e aceitação. O primeiro estágio corresponde à negação e ao isolamento, quando o paciente não aceita o diagnóstico de câncer, o que pode interferir na adesão ao tratamento, não persistindo por muito tempo. $\mathrm{Na}$ raiva o paciente apresenta revolta, tristeza, dor e ressentimento, perguntando-se por que eu? (SUSAKI; SILVA; POSSARI, 2006; KUBLER-ROSS, 2008).

Esta pergunta sugerida por Kübler-Ross foi relatada na fala do P5, o que demonstra a vivência da fase de raiva pelo paciente entrevistado. Neste momento a equipe de enfermagem deve tentar acalmá-lo e ter paciência, pois outras fases virão.

A barganha é a fase onde o paciente suplica por Deus e pela cura, buscando que as coisas se tornem como eram antes do câncer, se transformando em uma corri- 
da desesperada contra o tempo. Na fase de depressão o paciente possui sentimento de grande sofrimento, dor, tristeza isolamento, culpa, desesperança e medo. Neste momento o paciente já passou pela raiva e encontra-se de frente com a perspectiva de perda (SUSAKI; SILVA; POSSARI, 2006; KUBLER-ROSS, 2008).

A última fase significa aceitação do próprio destino, pois nesta fase o paciente já não experimenta o desespero e não nega sua realidade, encontrando paz de espírito. A família e o paciente precisam ser confortados e receberem apoio da equipe de enfermagem. Nem sempre o paciente consegue vivenciar esta última fase (SUSAKI; SILVA; POSSARI, 2006; KUBLER-ROSS, 2008).

O trabalho desenvolvido por Kubler-Ross pode subsidiar um melhor preparo do enfermeiro e equipe para lidar com o paciente oncológico e familiares. $\mathrm{O}$ reconhecimento das fases que o paciente e a família podem enfrentar durante o processo de adoecimento e tratamento pode ser base da humanização da assistência, princípio norteador da ética do cuidar.

\subsection{CONCEPÇÃO DE ESPIRITUALIDADE}

A concepção de espiritualidade perpassa acreditar em Deus e ter fé:

\section{P1: "DEUS em primeiro lugar".}

P2: "Adorar a DEUS em primeiro lugar em espírito e verdade".

P3: "Acreditar em DEUS".

P4: "Ter muita Fé, acreditar em DEUS".

P6: "Acreditar em DEUS, única forma de encontrar Ele, na força, na fé, quero dar meu testemunbo na igreja, pois sei que vou vencer".

P7: "Única forma de encontrarmos DEUS".

P8: "Acreditar em DEUS, Ele é bom, é maravilhoso tenbo bastante esperança".

P9: "Ter fé".

P10: "Crer em DEUS".

Em nossa sociedade, embora haja uma evolução, a oncologia ainda é considerada uma doença incurável, que aproxima as pessoas da morte. O familiar e o pa- ciente diante da situação e de tanto sofrimento buscam religiosidade, espiritualidade como sentido positivo ou negativo diante das novas experiências (GERRERO et al., 2011).

Compreende-se que a relação entre a espiritualidade e o câncer é sintetizada como: 'O câncer amedronta e a espiritualidade renova' (GUERRERO et al., 2011).

A relação entre espiritualidade e resiliência tem sido considerada algo de satisfação e conforto para enfrentamentos de situações consideradas difíceis. Espiritualidade em sentido positivo são aquelas que têm melhoras na saúde mental, redução de estresse, crescimento espiritual e cooperatividade. E negativas na qualidade de vida, quando o indivíduo renuncia ao tratamento por acreditar em cura divina (FORNAZARI; FERREIRA, 2010).

A dor novamente foi citada na fala do paciente P5, sexo masculino, 56 anos, com câncer no rosto, o que determina períodos de desalento e descrença para o processo de cura:

P5: "Acreditar em Deus tem horas que acredito e desacredito ao mesmo tempo, a gente luta, luta e não consegue objetivos tão mínimos, só queria minba saúde, tirar a dor, só isso".

"Cerca de $80 \%$ dos pacientes oncológicos tem dor não tratada adequadamente em algum momento de sua doença" (SILVA et al., 2014, p. 130).

Segundo estimativa da Organização Mundial da Saúde (OMS), das "cinco milhões de pessoas que morrem de câncer a cada ano, quatro milhões morrem com dor não controlada" (MORETE; MINSON, 2010, p. 75).

"Dor é uma importante causa de depressão, sensação de impotência e abandono. Gera um processo de retroalimentação: dor - depressão - mais dor" (SILVA et al., 2014, p. 130).

Um dos princípios mais importantes no cuidado oncológico é proporcionar alívio da dor e de outros sintomas angustiantes, porque se a dor física não estiver aliviada ou controlada, as necessidades das dimensões espirituais, sociais, emocionais não serão sanadas (PIMENTA; MOTA; CRUZ, 2006). 


\subsection{A INFLUÊNCIA DA ESPIRITUALIDADE NA RESILIÊN- CIA DO PACIENTE PARA ENFRENTAR O PROCESSO DE ADOECIMENTO E TRATAMENTO}

Todos os pacientes entrevistados consideram que existe influência da espiritualidade na resiliência para enfrentar o processo de adoecimento e tratamento. A fé remove montanhas; oferece força, suporte e sustentação quando não conseguimos mais avançar.

P1: "Sim, pois é em DEUS que encontramos força para continuar".

P2: "Sim existe, a fé remove montanbas".

P3: "Sim, pois é através da minha fé que consigo suportar".

P4: "Sim, acredito muito em DEUS, minha vontade de continuar vivendo vem dele".

P5: "Existe muita influência sim, acredito muito em DEUS, e creio que através das orações de meus amigos e minha, tenbo força para suportar tudo isso".

P6: "Acredito ter influência, pois tenho muita fé e sei que vou vencer".

P7: "Sim acredito muito em DEUS, tenbo fé $e$ somente a partir dele para ter, dar força pra continuar vivendo e estar enfrentando todos os dias essa doença".

P8: "Sim, só estou aqui boje porque tenbo muita fé, senão não estaria mais".

P9: "Existe, sem fé não somos nada, e tudo isso éfé".

P10: "Sim, tendo fé a gente alcança muita coisa, acredito em DEUS".

A espiritualidade e a resiliência podem ser uma forma de estratégia de enfrentamento de cada paciente perante seu diagnóstico, onde o próprio paciente poderá atribuir significado ao seu processo cura-doença, em busca da qualidade e sobrevivência se apegando à fé, para aliviar o sofrimento e, assim, obter maior esperança/expectativa de cura durante o tratamento, enfrentamentos estes adquiridos na vida social (GERRERO et al., 2011).

\subsection{AS TRANSFORMAÇÕES QUE SURGIRAM NA VIDA} DO PACIENTE A PARTIR DO PROCESSO VIVENCIADO

Todos os pacientes relataram as transformações que surgiram na vida a partir do processo vivenciado: na rotina familiar, nas atividades de vida diária e na própria fé em Deus.

P1: "Tudo, minha vida mudou completamente".

P4: "Tudo, a vida mudou completamente".

O diagnóstico de câncer em muitas vezes conduz à fase de ansiedade e muita aflição desencadeando assim um quadro de depressão. Isto está associado a sintomas como: perda de apetite e fadiga que também, por sua vez, podem estar associadas ao catabolismo da doença ou tratamento (SOUZA; FORTES, 2012).

$\mathrm{O}$ impacto do processo de adoecimento em virtude do câncer nas atividades de vida diária foi ressaltado nos relatos dos pacientes P3; P5; P6; P7; P10:

P3: "Todo contexto familiar e minhas rotinas".

P5: "Mudou tudo, antes podia fazer as coisas, boje não consigo nem juntar um chinelo no chão".

P6: "Tudo que eu fazia boje não posso fazer mais".

P7: "Tudo bouve várias transformações, tudo que fazia antes boje não posso fazer nem a metade".

P10: "Mudou toda rotina, a gente não é mais a mesma pessoa, não dá de planejar nada, boje estou bem, amanhã já não sei como vou estar, fica difícil".

Os pacientes $\mathrm{P} 3$, $\mathrm{P} 8$ e $\mathrm{P} 9$ ressaltaram as mudanças ocorridas na estrutura familiar e o paciente $\mathrm{P} 9$ relatou a necessidade de apoio, suporte e ajuda da família:

P3: "Todo contexto familiar e minhas rotinas".

P8: "Mudou tudo, minba família principalmente se preocupa muito comigo". 
P9: "Tudo mudou, minba família mudou, preciso sempre da ajuda deles".

O impacto gerado pelo diagnóstico e as implicações dos tratamentos podem alterar a capacidade funcional, comprometendo o desempenho ocupacional ao dificultar a realização das atividades cotidianas e provocando importantes alterações na qualidade de vida dos pacientes. $\mathrm{O}$ câncer acarreta várias mudanças relativas à sua autonomia e independência, gerando dificuldades. A dependência e a perda da identidade geram angústias e medos, que prejudicam a função emocional e sua qualidade de vida, sendo esse aspecto intensificado entre as que vivenciam o tratamento oncológico (FANGEL et al., 2013).

Apegar-se a Deus surgiu como uma forma de saída e superação na vida do paciente P2, sexo masculino, 51 anos, com câncer de fígado, a partir do processo vivenciado:

P2: "Toda minha vida, o jeito foi se apegar a DEUS muito mais que antes".

Resiliência significa a capacidade do paciente de enfrentar e superar problemas e adversidades e conseguir neste processo um fortalecimento. A resiliência pode promover uma melhor adaptação e flexibilidade ao paciente em relação ao processo de adoecimento com melhor adesão ao tratamento (AMARO, 2013).

A resiliência e a fé do paciente oncológico podem propiciar força, superação dos desafios, conforto e esperança em relação a todo o processo de adoecimento e tratamento (FORNAZARI; FERREIRA, 2010). Através da resiliência e da fé o paciente pode atribuir significado à vivência imposta pelo câncer (GUERRERO et al., 2011).

\subsection{O AUXÍLIO ESPIRITUAL QUE A EQUIPE DE ENFER- MAGEM OFERECEU AO PACIENTE DURANTE O PROCESSO DE ADOECIMENTO}

Os pacientes $\mathrm{P} 4, \mathrm{P} 5, \mathrm{P} 10, \mathrm{P} 6, \mathrm{P} 8$ e $\mathrm{P} 9$ relataram ter recebido apoio espiritual da equipe de enfermagem; 0 paciente $\mathrm{P} 6$ também recebeu auxílio espiritual do médico e os pacientes P8 e P9 receberam apoio da psicóloga.

P4: "Sim, recebi apoio, me falaram que é para confiar em DEUS que tudo vai dar certo".
P5: "Recebi mas não foram todas, só algumas, muitas não estão nem aí pra nós, falaram que é para ter fé que DEUS é maior".

P10: "Recebi apoio da enfermagem, me falaram que é para acreditar que tudo vai dar certo".

P6: "Recebi bastante apoio da equipe de enfermagem, inclusive do médico, me falou que é para acreditar e ter muita fé e força que eu vou vencer".

P8: "Psicóloga me falou que para DEUS nada é impossivel, o importante é ter muita fé".

P9: "A equipe é bem unida, brincam comigo nas boras que tem que brincar, mas nas boras de levar a sério levam, a psicóloga falou muito de DEUS, disse que é para mim crer e acreditar que vou vencer".

A enfermagem vem destacando a importância de conhecer a religião e a espiritualidade como fontes de fortalecimento para o enfrentamento de doenças. A espiritualidade tem demonstrado impacto na saúde física, atuando como fator de prevenção, menor abuso de drogas, menor incidência de suicídios, melhor qualidade de vida, maior sobrevida e menor tempo de internação. A espiritualidade relacionada à saúde tem se tornado paradigma a ser estabelecido na prática pela enfermagem. A prática diz que a enfermeira não responde somente pelo que é material em sua atenção com o paciente, mas por um ser que tem vida e que sofre no seu todo: corpo, mente e espírito (TOMASSO; BELTRAME; LUCCHETTI, 2011).

Os pacientes $\mathrm{P} 1, \mathrm{P} 2$, $\mathrm{P} 3$ e $\mathrm{P} 7$ ressaltaram não ter recebido apoio espiritual:

\section{P1: "Em nenbum momento".}

P2: "Não tive nenbum auxílio por parte deles".

P3: "Em nenbum momento recebi auxílio espiritual da equipe".

P7: "Não tive apoio da enfermagem, eles nem dão muita importância".

No processo de adoecimento com câncer, manifestam-se, no paciente, sentimentos de medo e angústia, os quais devem ser identificados, respeitados e tratados pela equipe de enfermagem. Não propomos um discurso 
religioso, pois o respeito à crença de cada pessoa é indiscutível, como preveem tanto a espiritualidade quanto a bioética. Pensamos em um acolhimento abrangente com o qual podemos demonstrar amor e interesse pela sua vida, auxiliando-o a tornar sua morte mais serena (SELLI; ALVES, 2007).

A fé religiosa enaltece tendo como principal resultado a esperança, fortalecimento e equilíbrio, uma luta maior pela vida, e tempo para aceitar a doença. A fé aparece como um ponto de satisfação e conforto para momentos diversos da vida, sendo assim uma importante aliada às pessoas que sofrem (TEIXEIRA; LEFEVRE, 2008).

Como o paciente pode encontrar novamente o caminho da esperança? Como ser resiliente frente a tantos dissabores e tantas lutas enfrentadas no cotidiano e nem sempre vencidas? Como ser persistente frente às várias dificuldades que o câncer impõe?

O suporte espiritual pode acontecer através da vivência da fé e das crenças pessoais do paciente, e também pode ser experimentado através de práticas que levam à interiorização, ao silêncio, a um contato mais profundo consigo mesmo. Esse contato pode não só aplacar dores e trazer mais sentido para as dificuldades, mas elevar o paciente e ajudá-lo a confiar em suas próprias forças, algumas vezes escondidas pelo desconforto e pela desesperança (MALUF; BUZAID; VARELLA, 2015).

A equipe de enfermagem que atua em oncologia precisa desenvolver habilidades, tais como ter cuidado e interesse pelo outro, dar-se, estar aberto para discutir a fé, encorajar a esperança, escutar atentamente, demonstrar confiança e honestidade, orar a pedido da família ou do paciente, tocar a pessoa, dar abertura, ajudar o paciente no encerramento das questóes do passado e amar (PIMENTA; MOTA; CRUZ, 2006).

Acreditamos que é necessário estabelecer uma ética do cuidado o quanto antes, defender um tratamento em que a dignidade da pessoa humana esteja em primeiro lugar. Devemos desenvolver atitudes morais e compromissadas com o bem-estar de nossos pacientes, resguardando com isso um percurso de tratamento mais harmonioso, resolutivo e, consequentemente, menos sofrido (SILVA et al., 2014, p. 132).
Nesta perspectiva ética considera-se essencial que a equipe de enfermagem tenha no cuidado espiritual um alicerce para a humanização em oncologia.

\section{CONSIDERAÇÕES FINAIS}

Resiliência significa a capacidade de recuperar-se de adversidades, força, resistência, superação diante do processo de adoecimento e tratamento oncológico.

Todos os pacientes destacaram as dificuldades enfrentadas com o processo de adoecimento, relatando as transformações que surgiram na rotina familiar, nas atividades de vida diária e na própria fé em Deus.

Todos os pacientes entrevistados consideram que existe influência da espiritualidade na resiliência para enfrentar o processo de adoecimento e tratamento. A fé remove montanhas; oferece força, suporte e sustentação quando não conseguimos mais avançar. Deus simboliza a superação diante da crise existencial.

A partir da reflexão proposta nesta pesquisa, sobre a importância da resiliência e espiritualidade na oncologia, considera-se primordial o cuidado de enfermagem espiritual ao paciente com câncer.

O cuidado espiritual é um grande desafio para a enfermagem, pois cuidar espiritualmente é humanizar, ouvir atentamente, estar presente na dor e no sofrimento, acalentar, ser flexível e aliar-se ao paciente e à família no processo de morte e morrer. Cuidar espiritualmente significa dar esperança de cura física ou, se isso não for possível, de cura espiritual com o perdão necessário para a passagem.

A espiritualidade é considerada uma forma de estratégia de enfrentamento e resiliência do paciente oncológico. O cuidado de enfermagem deve compreender a dimensão espiritual, ética, humana, sendo suporte nas horas de dor, presença na solidão e consolo na hora da partida.

O cuidado espiritual em enfermagem pode ser considerado base da humanização da assistência, princípio norteador da ética do cuidar. 


\section{REFERÊNCIAS}

AMARO, L. S. Resiliência em pacientes com câncer de mama: o sentido da vida como mecanismo de proteção. Logos \& Existência, v. 2, n. 2, p. 147-161, 2013. Disponível em: <https://www.google.com. $\mathrm{br} / \# \mathrm{q}=+\log \mathrm{os}+\% 26+$ exist $\% \mathrm{c} 3 \% 8$ ancia + revista + $\mathrm{da}+$ associa $\%$ c3\%87\%c3\%83o + brasileira + de + logoterapia $+\mathrm{e}+\mathrm{an} \% \mathrm{c} 3 \% 81$ lise + existencial $+2+(2) \% 2 \mathrm{c}+$ 147-161\%2c+2013 > . Acesso em: 02 out. 2014.

BRASIL. Conselho Nacional de Saúde. Resolução no $\mathbf{4 6 6}$, de 12 de dezembro de 2012. Disponível em: < http:// conselho.saude.gov.br/resolucoes/2012/Reso466.pdf $>$. Acesso em: 08 out. 2014.

COSTA, A. I. S.; CHAVES, M. D. Dor em pacientes oncológicos sob tratamento quimioterápico. Rev. Dor. São Paulo, v. 13, n. 1, Mar. 2012. Disponível em: <http:// www.scielo.br/scielo.php?script $=$ sci_arttext\&pi$\mathrm{d}=$ S1806-00132012000100008\&lng $=\mathrm{en} \& \mathrm{nrm}=\mathrm{iso}>$. Acesso em: 28 mar. 2015.

FANGEL, L. M. V.; PANOBIANCO, M. S.; KEBBE, L. M.; ALMEIDA, A. M.; GOZZO, T. O. Qualidade de vida e desempenho de atividades cotidianas após tratamento das neoplasias mamárias. Acta paul. enferm. São Paulo, v. 26, n. 1, 2013. Disponível em: <http:// www.scielo.br/scielo.php?script $=$ sci_arttext \&pi$\mathrm{d}=$ S0103-21002013000100015\&lng $=\mathrm{en} \& \mathrm{nrm}=\mathrm{iso}>$. Acesso em: 28 mar. 2015.

FORNAZARI, S. A.; FERREIRA, R. E. R. Religiosidade/espiritualidade em pacientes oncológicos: qualidade de vida e saúde. Psic.: Teor. e Pesq. Brasília, v. 26, n. 2, Jun 2010. Disponível em: <http:// www.scielo.br/scielo.php?script $=$ sci_arttext \& pi$\mathrm{d}=$ S0102-37722010000200008\&lng $=\mathrm{en} \& \mathrm{nrm}=\mathrm{iso}>$. Acesso em: 17 set. 2014.

GUERRERO, G. P.; ZAGO, M. M. F.; SAWADA, N. O.; PINTO, M. H. Relação entre espiritualidade e câncer: perspectiva do paciente. Rev. bras. enferm. Brasília, v. 64, n. 1, fev. 2011. Disponível em: <http:// www.scielo.br/scielo.php?script $=$ sci_arttext\&pi$\mathrm{d}=$ S0034-71672011000100008\&lng $=\mathrm{en} \& \mathrm{nrm}=\mathrm{iso}>$.
Acesso em: 17 set. 2014.

INCA. Instituto Nacional de Câncer. Coordenação de Prevenção e Vigilância. Estimativa 2014: Incidência de Câncer no Brasil. Rio de Janeiro: INCA, 2014. 124p.

KÜBLER-ROSS, E. Sobre a morte e o morrer. $9^{a}$ ed. São Paulo: Martins Fontes, 2008. 295p.

MALUF, F.; BUZAID, A. C.; VARELLA, D. Espiritualidade e auto-cuidado: vencer o câncer. 2015. Disponível em: $<$ http://vencerocancer.com.br/cuidados-integrativos/espiritualidade-e-autocuidado/> . Acesso em: 15 abr. 2015.

MINAYO, M. C. S. (Org.). Pesquisa social: teoria, método e criatividade. 21. ed. Petrópolis: Vozes, 2009.

MORETE, C. M.; MINSON, F. P. Instrumentos para a avaliação da dor em pacientes oncológicos. São Paulo: Hospital Israelita Albert Einstein, 2010.

PAULA JUNIOR, W.; ZANINI, D. S. Pacientes em radioterapia: um estudo de coping. Psic. Saúde \& Doenças, Lisboa, v. 13, n. 2, 2012. Disponível em: < http://www. scielo.gpeari.mctes.pt/scielo.php?script $=$ sci_arttext\&pi$\mathrm{d}=$ S1645-00862012000200024\&lng $=\mathrm{pt} \& \mathrm{nrm}=$ iso $>$. Acesso em: 09 set. 2014.

PIMENTA, C. A. M.; MOTA, D. D. C. F.; CRUZ, D. A. L. M. Dor e cuidados paliativos. São Paulo: Manole, 2006. 498p.

SALCI, M. A.; MARCON, S. S. Enfrentamento do câncer em família. Texto contexto - enferm. Florianópolis, v. 20, n. spe, 2011. Disponível em: <http:// www.scielo.br/scielo.php?script $=$ sci_arttext\&pi$\mathrm{d}=$ S0104-07072011000500023\&lng $=$ en\& $\mathrm{nrm}=$ iso $>$. Acesso em: 02 out. 2014.

SANTICHI, E. C.; BENUTE, G. R. G.; JUHAS, T. R.; PERARO, E. C.; LUCIA, M. C. S. Rastreio de sintomas de ansiedade e depressão em mulheres em diferentes etapas do tratamento para o câncer de mama. Psicol. hosp. São Paulo, v. 10, n. 1, jan. 2012. Disponível em: < http:// pepsic.bvsalud.org/scielo.php?script $=$ sci_arttext\&pi$\mathrm{d}=$ S1677-74092012000100004\&lng $=\mathrm{pt \& nrm}=$ iso $>$. Acesso em: 28 fev. 2015. 
SELLI, L.; ALVES, J. S. O cuidado espiritual ao paciente terminal no exercício da enfermagem e a participação da bioética. Bioethikos, v. 1, n. 1, p. 43-52, 2007. Disponível em: <http://www.saocamilo-sp.br/pdf/bioethikos/54/O_ cuidado_espiritual.pdf $>$. Acesso em: 17 set. 2014.

SILVA, J. A. G.; BERNAT, A. B. R.; PEREIRA, D. R.; SWINERD, M. Sofrimento psíquico do paciente oncológico: o que há de específico? Rio de Janeiro: Instituto Nacional de Câncer - INCA, 2014. 168p.

SILVA, J. A. G. Estimativa 2014: incidência de câncer no Brasil. Rio de Janeiro: INCA, 2014. 25p. Disponível em: < http://pt.scribd.com/doc/208732913/estimativa >. Acesso em: 24 jan. 2014.

SILVA, R. C. V.; CRUZ, E. A. Planejamento da assistência de enfermagem ao paciente com câncer: reflexão teórica sobre as dimensões sociais. Esc Anna Nery. Rio de Janeiro, v. 15, n. 1, mar. 2011. Disponível em: http://www.scielo.br/scielo.php?script $=$ sci_arttext\&pi$\mathrm{d}=$ S1414-81452011000100025\&lng $=\mathrm{en} \& \mathrm{nrm}=$ iso $>$. Acesso em: 08 out. 2014.

SÓRIA, D. A. C.; BITTENCOURT, A. R.; MENEZES, F. B.; SOUSA, C. A. C.; SOUZA, S. R. Resiliência na área da Enfermagem em Oncologia. Acta paul. enferm. São Paulo, v. 22, n. 5, out. 2009. Disponível em: <http:// www.scielo.br/scielo.php?script $=$ sci_arttext\&pi$\mathrm{d}=$ S0103-21002009000500017\&lng $=$ en $\& n r m=$ iso $>$. Acesso em: 09 set. 2014.

SOUZA, J. A.; FORTES, R. C. Qualidade de Vida de Pacientes Oncológicos: Um Estudo Baseado em Evidências. Rev Divulg Científ Sena Aires, n. 2, p. 183-192, jul/dez. 2012. Disponível em: < revistafacesa.senaaires.com.br/ index.php/revisa/article/download/30/25>. Acesso em: 05 abr. 2015.

SUSAKI, T. T.; SILVA, M. J. P.; POSSARI, J. F. Identificação das fases do processo de morrer pelos profissionais de Enfermagem. Acta paul. enferm. São Paulo, v. 19, n. 2, jun 2006. Disponível em: <http:// www.scielo.br/scielo.php?script $=$ sci_arttext\&pi$\mathrm{d}=$ S0103-21002006000200004\&lng $=\mathrm{en} \& \mathrm{nrm}=$ iso $>$. Acesso em: 28 mar. 2015.
TEIXEIRA, J. J. V.; LEFEVRE, F. Significado da intervenção médica e da fé religiosa para o paciente idoso com câncer. Ciênc. saúde coletiva. Rio de Janeiro, v. 13, n. 4, ago. 2008. Disponível em: <http:// www.scielosp.org/scielo.php?script $=$ sci_arttext\&pi$\mathrm{d}=$ S1413-81232008000400021\&lng $=$ en\& $\mathrm{nrm}=$ iso $>$. Acesso em: 10 set. 2014.

TEIXEIRA, R. J.; PEREIRA, M. G. Impacto do câncer parental no desenvolvimento psicológico dos filhos: uma revisão da literatura. Psicol. Reflex. Crit. Porto Alegre, v. 24, n. 3, 2011. Disponível em: < http:// www.scielo.br/scielo.php?script $=$ sci_arttext\&pi$\mathrm{d}=$ S0102-79722011000300012\&lng $=$ en $\& \mathrm{nrm}=$ iso $>$. Acesso em: 14 mar. 2012.

TOMASSO, C. S.; BELTRAME, I. L.; LUCCHETTI, G. Conhecimentos e atitudes de docentes e alunos em enfermagem na interface espiritualidade, religiosidade e saúde. Rev. Latino-Am. Enfermagem. Ribeirão Preto, v. 19, n. 5, out. 2011. Disponível em: <http:// www.scielo.br/scielo.php?script $=$ sci_arttext\&pi$\mathrm{d}=$ S0104-11692011000500019\&lng $=\mathrm{en} \& \mathrm{nrm}=\mathrm{iso}>$. Acesso em: 12 set. 2014.

Recebido em: 05 julbo 2015 Revisado em: 15 janeiro 2016 Aceito em: 29 fevereiro 2016 